\title{
Educação étnico-racial na escola: a Lei 10639/2003 e os desafios da interdisciplinaridade para além das aulas de história
}

\author{
Ethnic-racial education in schools: the Law 10639/2003 and \\ interdisciplinarity challenges beyond history lessons
}

\section{Daniel Luciano Gevehr \\ Darlã de Alves}

Faculdades Integradas de Taquara - FACCAT - Taquara - Rio Grande do Sul - Brasil

\begin{abstract}
Resumo: Analisa-se o ensino da cultura afro-brasileira e africana no contexto escolar, a partir de uma perspectiva interdisciplinar. Iniciamos o estudo, a partir de um levantamento que procurou reunir publicações nacionais sobre o tema da cultura afrobrasileira e africana. A partir deste levantamento, discutimos as diversas possibilidades de abordagem do tema são tornadas obrigatórias a partir da publicação da Lei 10639/2003. A Lei que determina o ensino de cultura afro-brasileira e africana na educação básica permite a proposição de ações e práticas pedagógicas, que tratam da cultura afro-brasileira e africana a partir de projetos interdisciplinares no currículo escolar. Para tanto, discutimos a aplicação de uma proposta interdisciplinar realizada em uma escola da rede municipal de Campo Bom (RS).
\end{abstract}

Palavras-chave: Educação étnico-racial. História e Cultura Afro-brasileira e Africana. Interdisciplinaridade.

Abstract: Analyzes the teaching of African-Brazilian and African culture in the school context, from an interdisciplinary perspective. We began the study, from a survey that sought to gather national publications on the subject of African-Brazilian and African culture. From this survey, we discussed the different approach to the subject possibilities are made mandatory from the publication of Law 10639/2003. The Law determines the teaching African-Brazilian and African culture in basic education allows us to propose actions and pedagogical practices, dealing with African-Brazilian and African culture from interdisciplinary projects in the school curriculum. Therefore, we discuss the implementation of an interdisciplinary proposal in a school municipal Campo Bom (RS).

Keywords: Ethnic-racial education. African-Brazilian and African history and culture. Interdisciplinarity. 


\section{Introdução}

Acabar com o pensamento de um modelo único de ensino é um dos grandes desafios na formação de professores Araújo e Yoshida (2016). No campo da educação há necessidade de se estar atento às diversas mudanças, aberto a novos conhecimentos e abordagens que auxiliem no processo de redefinição da profissão e de melhor compreensão da prática, criando assim, novas estratégias de aprendizagem, atendendo às demandas do saber e da sociedade, em constante mudança.

Um assunto que vem promovendo inúmeros debates e reflexões é o que se refere à educação étnico-racial. Inserida no currículo escolar por meio da Lei 10639/2003, traz a perspectiva de uma educação para equidade racial, através da obrigatoriedade do ensino de história e cultura afro-brasileira e africana na educação básica. A aprovação desta normativa tem provocado uma reflexão sobre o currículo instituído em nossas escolas, que, historicamente, tem negligenciado as diferenças culturais e valores civilizatórios africanos e afrodescendentes em nossa sociedade (MOREIRA e SANTANA, 2013).

Nesta perspectiva, se coloca a necessidade de trazer para o ensino da diversidade as diversas experiências culturais e conhecimentos sobre as ancestralidades - antes não contempladas - exigindo do professor preparo suficiente para a mediação deste conteúdo. Buscaremos responder, com este estudo, a seguinte questão problema: O ensino de história e cultura afro-brasileira e africana nas escolas está sendo realizado de forma interdisciplinar? Ou apenas abordado pelas disciplinas de história e ou literatura? Nesse sentido, discutimos possibilidades de trabalho com a temática, no contexto da educação básica brasileira, contribuindo assim, para o diálogo sobre as estratégias de ensino.

Alinhada a questão problema se traçou 0 objetivo geral, que é de discutir possibilidades pedagógicas para o ensino de história e cultura afrobrasileira e africana empregados nas escolas de educação básica, a partir da alteração da LDB com a normativa da Lei 10639/2003 e como essas questões podem se articular com os conteúdos e ações desenvolvidas pelas diferentes disciplinas do currículo escolar.

As respostas encontradas para esta questãoproblema contribuem para fomentar os debates sobre o assunto e aprofundar o debate deste tema nos currículos. Percebemos que o tema pode ser abordado de forma interdisciplinar, também em práticas pedagógicas específicas de cada disciplina. Traz-se, como forma de exemplificar esta prática, um exemplo de um projeto pedagógico realizado em uma escola da rede municipal da cidade de Campo Bom (RS).

A justificativa para esta pesquisa é de que a alteração da LDB, proposta pela Lei 10639/2003, dá início a uma nova abordagem sobre a diversidade cultural no ambiente escolar. Anteriormente a esta determinação, o currículo de história abordava a cultura afro-brasileira e africana na perspectiva do negro escravo, submisso ao senhor de engenho aspecto que hoje ainda é identificado em currículos escolares e materiais didáticos.

Nesse sentido, é fundamental lembrar que a história do negro no Brasil não se resume à escravidão. Este foi um grande episódio. Porém, limitar a identidade do negro afro-brasileiro e africano apenas a este acontecimento é ignorar toda sua historicidade e sua matriz cultural, que contribuiu para a formação da cultura do nosso país e do ser brasileiro. Acredita-se na educação étnico-racial, como forma de conhecimento e valorização da cultura de todos brasileiros, buscando a equidade racial e eliminação do preconceito (AMARO, 2015). A proposição de políticas de ações afirmativas no Brasil, que contemplem uma educação voltada para o combate ao racismo e a promoção da igualdade racial na escola são questões urgentes na contemporaneidade.

A escola onde foi realizada a prática está situada na região do Vale do Rio do Sinos, em Campo Bom (RS) e pertence à rede municipal de ensino. Possui turmas apenas dos anos iniciais do ensino fundamental do $1^{\circ}$ ao $5^{\circ}$ anos. 
Situada em um bairro de classe média da cidade, Genuíno Sampaio, cujo mesmo dá nome à escola, a instituição atende 108 alunos de nove diferentes bairros da cidade de Campo Bom (RS). Entre os alunos estão distribuídos 63 meninas e 45 meninos, sendo 60 deles brancos e 48 pretos ou pardos, segundo o censo escolar 2015. Em seu grupo de trabalho a escola possui 25 funcionários, onde destes 18 professores, de diversas disciplinas, atuantes junto às turmas, 1 auxiliar administrativa, 1 coordenadora pedagógica, 1 diretora, 1 cozinheira, 2 auxiliares de serviços gerais e 1 auxiliar de biblioteca. No documento balizador para a construção do currículo da escola, o Projeto Político Pedagógico (PPP), consta como filosofia da escola o respeito à diversidade humana, social, econômica e étnica. Dando justificativa à iniciativa de realização deste trabalho interdisciplinar com o objetivo de evidenciar a cultura afro-brasileira em um contexto de diversidade.

Esta região tem em seu processo histórico de formação a marca da colonização alemã e cultiva, até os dias atuais, a cultura germânica em origem. Observa-se, quase que uma total invisibilidade dos demais grupos na formação do município, que se afirma, como um município de origem germânica em razão de sua ligação com o antigo municípiosede, que é São Leopoldo, e do qual Campo Bom se emancipou.

Segundo o Censo Demográfico (IBGE, 2010), Campo Bom possui uma grande parcela de afrobrasileiros em sua população, advindos de algumas regiões do Estado. Isto contribuiu para a formação da diversidade étnica cultural da população residente no município. Já a escola selecionada para a prática, contempla alunos oriundos de nove bairros da cidade. Possuindo alunos de todas as esferas sociais, seja de vulnerabilidade social à média alta. Consequentemente, este público de alunos se caracteriza pela diversidade cultural.

\section{Texto e contexto da pesquisa}

Procurando contextualizar a discussão à qual nos propomos, realizamos uma revisão sistemática sobre o tema em questão e que traz uma análise de artigos científicos publicados em periódicos nacionais, assim como da análise de conteúdo, apresentados nestas publicações. Para selecionar os artigos científicos utilizados nesta pesquisa fez-se uso das palavras-chave "Educação étnico-racial. Ensino. Cultura afro-brasileira. Cultura africana." entre o período de 2003 a 2015.

Por meio desta seleção foram encontrados 37 artigos científicos, que em seguida foram estudados para verificar sua pertinência para a pesquisa e se abordavam em seu estudo alguma ferramenta de ensino da Cultura afro-brasileira e africana. Entre estes 19 artigos abordavam alguma ferramenta de ensino, e a partir desses artigos desenvolveu-se um estudo detalhado. Os artigos que compõem este estudo foram selecionados na base de dados Scielo e Periódicos Capes.

Ressaltamos que o objetivo de nossa pesquisa não é evidenciar apenas as produções da área de história, mas também de outras áreas, como a literatura, a geografia, as artes, uma vez que o próprio objetivo do trabalho já evidencia seu caráter interdisciplinar, trazendo a ideia "da interdisciplinaridade para além das aulas de história".

É importante ressaltar que outras bases de dados foram consultadas na pesquisa, tais como a ANPUH - Associação Nacional de História, através do seu periódico, a Revista Brasileira de História e a ANPEd - Associação Nacional de Pós-Graduação e Pesquisa em Educação, por meio da sua publicação trimestral, que é a Revista Brasileira de Educação. Estas, por sua vez, estão diretamente ligadas à base de dados Scielo, e consequentemente a busca realizada nesta última base citada engloba produções disponíveis nas edições publicadas da Revista Brasileira de História e na Revista Brasileira de Educação.

A Associação Nacional de História - ANPUH que é responsável pela publicação da Revista Brasileira de História e pela Revista História Hoje, também foi consultada através da base de dados dos seus periódicos, a fim de amparar a discussão e fomentar o debate sobre a temática abordada. Nelas 
foram encontradas diversas produções com a temática racial.

Porém estas produções tratavam essencialmente do negro durante o período escravagista - ou seja, na condição de escravo - não abordando diretamente a educação étnico-racial. Dessa forma, deixamos claro que a pesquisa não teve como objeto de investigação as produções científicas resultantes dos GT's (Grupos de Trabalho) da ANPUH e da ANPEd - nos quais evidentemente existe produção sobre o tema em questão - mas sim as publicações de seus periódicos oficiais. Vale ressaltar, no entanto, que duas edições da Revista Brasileira de História abordaram a etnia negra, em forma de Dossiê Temático. O quadro 1 indica as publicações da edição n'52 da RBH:

Quadro 1

\begin{tabular}{|c|c|c|c|c|c|}
\hline Artigos & Periódico & Temática & Volume & $\mathrm{N}^{0}$ & Ano \\
\hline $\begin{array}{l}\text { Escravos daqui, dali e de mais além: o } \\
\text { tráfico interno de cativos em } \\
\text { Constituição (Piracicaba), 1861-1880. }\end{array}$ & $\mathrm{RBH}$ & Escravidão & 26 & 52 & 2006 \\
\hline $\begin{array}{l}\text { As muitas faces do compadrio de } \\
\text { escravos: o caso da Freguesia de São } \\
\text { José dos Pinhais (PR), na passagem do } \\
\text { século XVIII para o XIX. }\end{array}$ & $\mathrm{RBH}$ & Escravidão & 26 & 52 & 2006 \\
\hline $\begin{array}{l}\text { Escravos do Atlântico equatorial: tráfico } \\
\text { negreiro para o Estado do Maranhão e } \\
\text { Pará (século XVII e início do século } \\
\text { XVIII). }\end{array}$ & $\mathrm{RBH}$ & Escravidão & 26 & 52 & 2006 \\
\hline $\begin{array}{l}\text { Esperanças e desventuras de escravos } \\
\text { e libertos em Vitória e seus arredores } \\
\text { ao final do século XIX. }\end{array}$ & $\mathrm{RBH}$ & Escravidão & 26 & 52 & 2006 \\
\hline $\begin{array}{l}\text { Cartas de alforria: "para não ter o } \\
\text { desgosto de ficar em cativeiro". }\end{array}$ & $\mathrm{RBH}$ & Escravidão & 26 & 52 & 2006 \\
\hline $\begin{array}{l}\text { A morte do senhor e o destino das } \\
\text { famílias escravas nas partilhas: } \\
\text { Campinas, século XIX. }\end{array}$ & $\mathrm{RBH}$ & Escravidão & 26 & 52 & 2006 \\
\hline $\begin{array}{l}\text { A África carioca em lentes europeias: } \\
\text { corpos, sinais e expressões. }\end{array}$ & $\mathrm{RBH}$ & Escravidão & 26 & 52 & 2006 \\
\hline $\begin{array}{l}\text { Escravos sem senhores: escravidão, } \\
\text { trabalho e poder no mundo romano. }\end{array}$ & $\mathrm{RBH}$ & Escravidão & 26 & 52 & 2006 \\
\hline
\end{tabular}


Já o quadro 2 mostra as produções da edição n69, que tem por temática o pós abolição. No quadro apresentamos os títulos dos artigos publicados na edição da revista:

Quadro 2

\begin{tabular}{|c|c|c|c|c|c|}
\hline Artigos & Periódico & Temática & Volume & $\mathrm{N}^{0}$ & Ano \\
\hline $\begin{array}{l}\text { No ritmo do Vagalume: culturas negras, } \\
\text { associativismo dançante e } \\
\text { nacionalidade na produção de } \\
\text { Francisco Guimarães (1904-1933). }\end{array}$ & $\mathrm{RBH}$ & $\begin{array}{l}\text { Pós- } \\
\text { abolição no } \\
\text { Mundo } \\
\text { Atlântico }\end{array}$ & 35 & 69 & 2015 \\
\hline $\begin{array}{l}\text { Revisitando "Família e Transição": } \\
\text { família, terra e mobilidade social no } \\
\text { pós-abolição: Rio de Janeiro (1888- } \\
\text { 1940). }\end{array}$ & $\mathrm{RBH}$ & $\begin{array}{l}\text { Pós- } \\
\text { abolição no } \\
\text { Mundo } \\
\text { Atlântico }\end{array}$ & 35 & 69 & 2015 \\
\hline $\begin{array}{l}\text { Sr. Sidão Manoel Inácio e a conquista } \\
\text { da cidadania: o campesinato negro do } \\
\text { Morro Alto e a República que foi. }\end{array}$ & $\mathrm{RBH}$ & $\begin{array}{l}\text { Pós- } \\
\text { abolição no } \\
\text { Mundo } \\
\text { Atlântico }\end{array}$ & 35 & 69 & 2015 \\
\hline $\begin{array}{l}\text { Teodoro Sampaio e Rui Barbosa no } \\
\text { tabuleiro da política: estratégias e } \\
\text { alianças de homens de cor (1880- } \\
\text { 1919). }\end{array}$ & $\mathrm{RBH}$ & $\begin{array}{l}\text { Pós- } \\
\text { abolição no } \\
\text { Mundo } \\
\text { Atlântico }\end{array}$ & 35 & 69 & 2015 \\
\hline $\begin{array}{l}\text { Campos do pós-abolição: identidades } \\
\text { laborais e experiência "negra" entre os } \\
\text { trabalhadores do café no Rio de Janeiro } \\
(1931-1964) \text {. }\end{array}$ & $\mathrm{RBH}$ & $\begin{array}{l}\text { Pós- } \\
\text { abolição no } \\
\text { Mundo } \\
\text { Atlântico }\end{array}$ & 35 & 69 & 2015 \\
\hline $\begin{array}{l}\text { As heranças do Rosário: associativismo } \\
\text { operário e o silêncio da identidade } \\
\text { étnico-racial no pós-abolição, Laguna } \\
\text { (SC). }\end{array}$ & $\mathrm{RBH}$ & $\begin{array}{l}\text { Pós- } \\
\text { abolição no } \\
\text { Mundo } \\
\text { Atlântico }\end{array}$ & 35 & 69 & 2015 \\
\hline $\begin{array}{l}\text { Os perigos dos Negros Brancos: cultura } \\
\text { mulata, classe e beleza eugênica no } \\
\text { pós-emancipação (EUA, 1900-1920) }\end{array}$ & $\mathrm{RBH}$ & $\begin{array}{l}\text { Pós- } \\
\text { abolição no } \\
\text { Mundo } \\
\text { Atlântico }\end{array}$ & 35 & 69 & 2015 \\
\hline $\begin{array}{l}\text { O legado das canções escravas nos } \\
\text { Estados Unidos e no Brasil: diálogos } \\
\text { musicais no pós-abolição. }\end{array}$ & $\mathrm{RBH}$ & $\begin{array}{l}\text { Pós- } \\
\text { abolição no } \\
\text { Mundo } \\
\text { Atlântico }\end{array}$ & 35 & 69 & 2015 \\
\hline
\end{tabular}

Fonte: Adaptado pelos autores. 
Também a Revista História Hoje traz em sua primeira edição do ano de 2012 um dossiê sobre o Ensino de História da África e cultura afro-brasileira. Estas produções contribuem, à luz do ensino de história, para a melhor compreensão e disseminação da educação étnico-racial nos currículos escolares.

Lembramos que para a análise dos artigos, inicialmente observou-se os títulos das obras e verificou-se que as palavras "Educação étnico-racial. Cultura afro-brasileira. Ensino. Cultura africana." predominaram devido ao fato de terem sido estas as palavras que foram usadas como critério de seleção dos artigos. Posteriormente, verificou-se quais artigos possuíam uma ferramenta de ensino ou atividade aplicada, abordando a temática História e Cultura Afro-brasileira e Africana. Foram observados também, os métodos utilizados pelos autores para concretizarem seus estudos. Estes métodos, bem como sua frequência nos artigos, estão elencados na Tabela abaixo:

Tabela 2 - Métodos de pesquisa usados nos artigos.

\begin{tabular}{c|c|c}
\hline Método & Frequência & Porcentagem \\
\hline $\begin{array}{c}\text { Simulação } \\
\text { besquisasa }\end{array}$ & - & $0 \%$ \\
\hline $\begin{array}{c}\text { Estudo de caso } \\
\text { múltiplo }\end{array}$ & - & $27 \%$ \\
\hline Survey & - & $0 \%$ \\
\hline Estudo de caso & 14 & $73 \%$ \\
\hline Não especificado & - & $0 \%$ \\
\hline Documental & - & $0 \%$ \\
\hline \multicolumn{2}{c|}{ Fonte: Dados da pesquisa. } & Total = 100\% \\
\hline \multicolumn{2}{c|}{}
\end{tabular}

A Tabela 2 evidencia que o método mais utilizado para a efetivação dos estudos foi o método estudo de caso, seguido pelo método de revisão bibliográfica. Desta forma, evidencia-se que a maioria dos estudos, parte de situações-problema que particularizam determinados recortes espaciais ou temporais. Através destes recortes, é que o tema é aprofundado.

No caso da Tabela 3, apresentada abaixo, classificamos o tipo de abordagem realizada sobre 0 tema ensino da cultura afro-brasileira e africana. Para tal levantamento, consideramos o período posterior à implantação da Lei (2003) que obriga o ensino dessas culturas na educação básica.

Tabela 3: Abordagem do tema cultura afrobrasileira e africana

\begin{tabular}{|c|c|}
\hline Autor & Abordagem de tema \\
\hline BARBOSA, Carla Cristina et al. & $\begin{array}{l}\text { Oficinas de cinema; Oficinas de } \\
\text { dança; Oficinas de música; } \\
\text { Gincana. }\end{array}$ \\
\hline FERREIRA, Cléa Maria da Silva. & Literatura; \\
\hline VALENTE, Ana Lúcia & Debates; Teatro. \\
\hline $\begin{array}{l}\text { FERNANDES, José Ricardo } \\
\text { Oriá }\end{array}$ & Literatura; \\
\hline $\begin{array}{l}\text { CASTRO, Cristiana Gonzaga } \\
\text { Candido de Souza et al }\end{array}$ & Literatura; \\
\hline PEREIRA, Júnia Sales & Literatura; \\
\hline PACÍFICO, Tânia Mara & Literatura; \\
\hline $\begin{array}{l}\text { COSTA, Raphael Luiz Silva da; } \\
\text { DUTRA, Diego França }\end{array}$ & Literatura; \\
\hline GOMES, IIma Lino & Literatura; \\
\hline $\begin{array}{l}\text { AGUIAR, Janaina Couvo } \\
\text { Teixeira Maia de; AGUIAR, } \\
\text { Fernando José Ferreira. }\end{array}$ & Literatura; \\
\hline $\begin{array}{l}\text { VERRANGIA, Douglas; } \\
\text { SILVA, Petronilha Beatriz } \\
\text { Gonçalves e }\end{array}$ & Literatura; \\
\hline $\begin{array}{l}\text { COẾLHO,Fares Frades; } \\
\text { COSTA, Wanderleya Nara } \\
\text { Gonçalves }\end{array}$ & Literatura; \\
\hline ROSA, Maria Cristina & $\begin{array}{l}\text { Manifestações artísticas de } \\
\text { artes plásticas; }\end{array}$ \\
\hline $\begin{array}{l}\text { MOREIRA, Marcos Alves; } \\
\text { SANTANA, José Valdir Jesus de }\end{array}$ & Literatura; \\
\hline $\begin{array}{l}\text { GUEDES, Elocir; } \\
\text { NUNES, Pâmela; } \\
\text { Tatiane de ANDRADE }\end{array}$ & Literatura; Concurso de beleza; \\
\hline $\begin{array}{l}\text { COELHO, Wilma de Nazaré } \\
\text { Baía; COELHO, Mauro Cezar }\end{array}$ & $\begin{array}{l}\text { Manifestações artísticas de } \\
\text { dança, canto e artes plásticas; } \\
\text { Concurso de beleza; }\end{array}$ \\
\hline $\begin{array}{l}\text { PAULA, Benjamin Xavier de; } \\
\text { GUIMARÃES, Selva }\end{array}$ & Literatura; \\
\hline SULEIMAN, Bianca Barbosa & Cinema; Literatura; \\
\hline $\begin{array}{l}\text { CARDOSO, Salete Rodrigues; } \\
\text { FEITOSA, Diane Mendes }\end{array}$ & Literatura; \\
\hline
\end{tabular}

Também a frequência com que cada tipo de abordagem aparece nestas publicações, pode ser observada na tabela que apresentamos logo abaixo. Através dela, percebemos uma clara preferência pela literatura, que é empregada na maioria dos casos, como forma de se discutir o tema na área da educação. Esse aspecto permite observar a importância exercida pela literatura, em especial a 
literatura brasileira, que através de suas publicações, tem dado visibilidade às questões de africanidades no Brasil. Além disso, a literatura permite, através da ficção, a abordagem de temas associados às africanidades e que revelam, em grande parte, cenas e personagens do cotidiano brasileiro.

Tabela 4 - Frequência das abordagens de ensino da cultura afro-brasileira e africana nos estudos

\begin{tabular}{c|c|c}
\hline $\begin{array}{c}\text { Abordagens de } \\
\text { ensino }\end{array}$ & Frequência & Porcentagem \\
\hline $\begin{array}{c}\text { Manifestações } \\
\text { artísticas de dança }\end{array}$ & 2 & $8 \%$ \\
\hline $\begin{array}{c}\text { Manifestações } \\
\text { artísticas de canto }\end{array}$ & 2 & $8 \%$ \\
\hline $\begin{array}{c}\text { Manifestações } \\
\text { artísticas de artes } \\
\text { plásticas }\end{array}$ & 1 & $3,5 \%$ \\
\hline $\begin{array}{c}\text { Manifestações } \\
\text { artísticas de teatro }\end{array}$ & 1 & $3,5 \%$ \\
\hline Concurso de beleza & 2 & $8 \%$ \\
\hline Literatura & 15 & $54 \%$ \\
\hline Cinema & 2 & $3,5 \%$ \\
\hline Gincana & 1 & $3,5 \%$ \\
\hline Debates & 1 & \\
\hline
\end{tabular}

Fonte: Elaborado pelos autores.

A escola, como instituição social voltada ao ensino, constitui-se como um dos principais espaços de formação dos indivíduos e encontra-se, centralmente envolvida na questão da diversidade racial existente na sociedade brasileira. Sendo pública, de todos e para todos, expõe uma prática contraditória ao privilegiar a cultura ocidental, quando, em parte, abstém-se aos demais pilares étnicos e culturais que compõem a base do ser brasileiro.

A Constituição de 1988 trouxe novamente à escola e, consequentemente à educação, um viés de mudança. Ampliando a gratuidade do ensino público em estabelecimentos oficiais, tornando obrigatório e gratuito o ensino fundamental, estendendo o ensino obrigatório e gratuito progressivamente ao ensino médio. $\mathrm{O}$ atendimento a crianças em creches e pré- escolas de 0 a 6 anos, a autonomia universitária, a distribuição dos recursos públicos através de diversos programas, dentre outras medidas (ARANHA, 2006).

A reforma constitucional incitou a reformulação das Diretrizes e Bases que regem a Educação Nacional. Assim, através do debate democrático com a comunidade educacional, em 1996, a nova Lei de Diretrizes e Bases da Educação Nacional (LDBEN) foi promulgada e está em vigor atualmente com algumas alterações (ARANHA, 2006).

Dentre as diversas mudanças, visou-se atender, por demanda, aos movimentos sociais quanto à temática de valorização à diversidade cultural e combate às desigualdades, privilegiando assim a pluralidade sociocultural, característica do povo brasileiro. Baseando-se no princípio ético de uma educação igualitária e inclusiva que considere a todos como sujeitos ativos na cultura, sem discriminar a qualquer grupo étnico (KADLUBITSKI e JUNQUEIRA, 2009).

Compreendendo a educação como principal pilar da sociedade contemporânea -detentora do poder de reafirmar ou não as relações existentes ela não é um espaço neutro, devendo assim ser compreendida como dinâmica e espaço de transformação. A partir desta perspectiva e da militância do movimento negro e de outros setores, em 2003 foi realizada para o campo educacional, a inclusão da Lei 10.639/2003 que altera a LDB:

O art. 26 e 79 da Lei de Diretrizes e Bases da Educação Nacional de 1996 estabelece:

Art. 26-A Nos estabelecimentos de ensino fundamental e médio, oficiais e particulares torna-se obrigatório o ensino sobre História e Cultura Afro-Brasileira.

$\mathrm{O}$ art. 79-B O calendário escolar incluirá o dia 20 de novembro como "Dia Nacional da Consciência Negra".

A LDB, Lei de 9394/1996, traz em seu primeiro artigo a afirmação de que a educação abrange os processos formativos que se desenvolvem na vida familiar, na convivência humana, no trabalho, nas instituições de ensino e pesquisa, nos movimentos sociais e organizações da sociedade civil e nas manifestações culturais (MOREIRA e SANTANA, 2013). Assim entendemos que conhecer a nossa 
história e herança africana faz parte do processo de formação dos sujeitos sociais e caracteriza uma significativa etapa da nossa formação histórica (MOREIRA e SANTANA, 2013).

Integrar culturas é seguir por um caminho "pedregoso", porém não intransponível. O propósito neste caso é tornar visível socialmente à importância da cultura africana no decorrer da formação étnica brasileira. É fixar na sociedade a reflexão histórica a respeito da significância da influência africana na formação dos pilares étnico-sociais do país. Este exercício social passou a ser defendido tardiamente no Brasil, devido não somente a grande extensão territorial, mas principalmente pela indiferença intencional oferecida a esta questão (GUEDES, NUNES e ANDRADE, 2013).

Promover a descolonização do saber e dar outra possibilidade de visão - que não seja eurocêntrica - é urgente para que esta meta seja atingida. Não se pode apenas acrescentar e ministrar novos conteúdos e acreditar que estamos - com isso - contribuindo para a formação escolar livre de discriminações raciais. Precisamos revisar esses conteúdos que de alguma forma reforçam o preconceito racial inferiorizando o negro (COSTA e DUTRA, 2009).

Para efetivar a aplicação da Lei n. ${ }^{\circ}$ 10.639/2003, os diretores, a equipe pedagógica e os professores precisam aprofundar o conhecimento teórico-metodológico sobre o tema e viabilizar condições para consolidação deste conhecimento, com a intenção de implantar na escola uma prática antirracista. Uma prática que repudie o racismo e qualquer forma de preconceito nas escolas pode contribuir para melhorar a aprendizagem e ajudar na manutenção dos alunos negros nas escolas, com voz e participação ativa neste processo (PACífICO, 2008).

Fernandes (2005), por sua vez, afirma que a inovação dessa nova proposta é a existência de temas transversais que deverão perpassar as diferentes disciplinas curriculares (Língua Portuguesa, Matemática, História, Geografia, Ciências e Artes) e permitir, com isso, a interdisciplinaridade. O autor ressalta que um dos gargalos do sistema educacional brasileiro reside na qualificação do corpo docente, sobretudo os que exercem o magistério nos anos iniciais do ensino fundamental.

Ainda neste mesmo sentido, Cardoso e Feitosa (2015) alertam que a qualificação dos professores torna-se urgente e necessária, haja vista que se constituem agentes responsáveis pelas discussões para combater, no ambiente escolar, o preconceito e toda a forma de discriminação social que têm sofrido as pessoas que se encontram à margem da sociedade. Completam dizendo que é necessário que a qualificação docente seja propiciada e incentivada no sentido de formar professores que reflitam criticamente sobre o seu fazer pedagógico.

Mesmo pressupondo ações interdisciplinares, o ensino de história é, no caso dessa regulamentação, considerado campo estratégico. 0 ensino de história relaciona-se com movimentos e processos de manipulação da memória e com diferentes tentativas de reconfiguração identitária em seus variados matizes (PEREIRA, 2008).

Em relação às práticas pedagógicas que contemplem a Lei 10693/2003, na disciplina de Geografia, Costa e Dutra (2009) defendem que a Geografia tem fundamental importância no processo de entendimento de mundo. E que o ensino analítico desta ciência pode propiciar a desconstrução destas formas hierarquizantes e preconceituosas de enxergar o mundo. Para posicionar-se no mundo o individuo precisa conhecê-lo. Através do estudo da Geografia pode-se percorrer o continente africano não apenas pela descrição do espaço ou pela historicidade dos acontecimentos na África - pela visão do europeu. A construção destas possibilidades, tanto para quem ensina quanto para quem aprende, é um exercício reflexivo de inserção de humanidade na educação (COSTA e DUTRA, 2009).

Já no ensino de Matemática, contribuindo com os expostos das práticas pedagógicas (KOLODZIEISKI, 2013) afirma que assim como as demais ciências, a Matemática faz parte de conhecimento e da aprendizagem dos indivíduos ao 
longo da vida escolar, assim ela também pode ser ensinada para além dos números, fórmulas e demonstrações e também é elemento importante para compor a aprendizagem da diversidade de cultura.

Como prática pedagógica a autora defende que na abordagem da origem dos sistemas de numeração, os números, contagem, medida, o professor ao ensinar contempla muitas vezes a história e cultura das civilizações egípcia, romana, maia e entre outras. Dessa mesma maneira quando os alunos iniciam a aprendizagem de contagem se aprende um pouco de história, assim também se pode relacionar a história e a cultura africana valorizando a cultura deste grupo e contribuindo para a mudança da sociedade através do estudo das curiosidades, das diferenças, da reflexão, da história e da cultura africana (KOLODZIEISKI, 2013).

Também no ensino das Artes Plásticas, (ROSA, 2012) afirma que quando o professor apresenta para seus alunos a arte europeia e estadunidense - como representação hegemônica da arte, sem propiciar o estudo de outras culturas - 0 professor está afirmando as relações de poder, racismo e estigmatização e distanciando-se de uma política inclusiva. O professor de arte tem encontrado na antropologia fonte para alimentar sua formação no que diz respeito à compreensão das artes plásticas afro-brasileiras, podendo explorar forma, estilo, cores, simbolismo, contexto e representação.

Verrangia e Silva (2010) nos mostram a aplicabilidade de práticas pedagógicas que relacionam o ensino da disciplina de ciências naturais e biologia à temática da educação étnico-racial. Atendendo a normativa federal e abordando de forma específica o tema na disciplina, os autores citados anteriormente relacionam cinco conteúdos a serem trabalhados: a) Impacto das Ciências Naturais na vida social e racismo; b) Superação de estereótipos, valorização da diversidade e Ciências Naturais; c) África e seus descendentes e o desenvolvimento científico mundial; d) Ciências, mídia e relações étnico-raciais; e) Conhecimentos tradicionais de matriz africana e afro-brasileira e Ciências.
Neste estudo, os autores mencionam, ainda, sobre a necessidade dos cursos de formação de professores em Ciências instigarem o questionamento dos processos de seleção dos conteúdos conceituais e procedimentais, para que de fato os cursos possam preparar professores para lidar pedagogicamente a com a diversidade étnico-racial.

É importante ressaltar que a escola é um ambiente privilegiado para a promoção de relações étnico-raciais positivas, em virtude da marcante diversidade em seu interior. Porém, não é a única instituição responsável pela educação das relações étnico-raciais, uma vez que o processo de educar ocorre também na família, nos grupos culturais, nas comunidades, no convívio social proporcionado pelos meios de comunicação, entre outros (VERRANGIA e SILVA, 2010).

Nesta discussão, cada um dos autores traz uma experiência de abordagem, discutindo proposições de atividades pedagógicas dentro de uma disciplina específica. Fernandes (2005), por sua vez, ressalta a importância da abordagem em caráter interdisciplinar, na qual o tema perpassa as disciplinas de forma a interligar os conhecimentos gerados através de suas práticas pedagógicas. Tratase, de um trabalho árduo, quando nos deparamos com currículos tradicionais de ensino. Para nos ajudar a pensar sobre esse desafio, o pensamento construtivista de Piaget (1973, p.142) apresenta um conceito claro sobre a interdisciplinaridade, enquanto "Uma colaboração entre disciplinas diversas ou entre setores heterogêneos de uma mesma ciência que conduz a interações propriamente ditas, isto é, a certa reciprocidade nas trocas, de tal modo que haja um total enriquecimento mútuo".

No Brasil, a CAPES também dialoga sobre esta questão, propondo um conceito sobre a interdisciplinaridade, visto que no âmbito em que opera, já realizou algumas mudanças para a definição correta das atividades e conceitos, sendo compreendida como. Neste sentido, para a CAPES (2013, p.12), a interdisciplinaridade se caracteriza pela "[...] convergência de duas ou mais áreas do conhecimento, não pertencentes à mesma classe, 
que contribua para o avanço das fronteiras da ciência e tecnologia, transfira métodos de uma para outra, gerando novos conhecimentos ou disciplinas [...]".

Partindo destas definições - tanto do campo da educação quanto da própria CAPES -

onde a interdisciplinaridade constrói conhecimento dos mais diversos saberes, frutos da complementação de duas ou mais ciências, que de forma conjunta abordam determinado tema é que foi criado o projeto "A AFRICANIDADE NO CONTEXTO ESCOLAR: DA LUDICIDADE ÀS RELAÇÕES PESSOAIS". Pensado pela coordenação pedagógica da escola localizada em Campo Bom (RS), como forma de atender a normativa federal da lei 10639/2003, foi proposto um trabalho que permitisse a interação das disciplinas na construção das práticas pedagógicas a serem desenvolvidas.

Com o objetivo de abordar, discutir e refletir sobre a questão da diversidade cultural, num processo de identificação com as identidades culturais (AMARO, 2015) - tendo como referencial a cultura de matriz africana -, é que as diferentes disciplinas que compõem o currículo dos anos iniciais do ensino fundamental na Escola Municipal de Ensino Fundamental Genuíno Sampaio, buscaram estabelecer um diálogo interdisciplinar. As disciplinas envolvidas foram Língua Portuguesa, Língua Inglesa, Literatura Brasileira, Ciências Físicas e Biológicas, Educação Artística, Educação Física, Música, Matemática, História, Geografia e Informática.

A partir disso estruturou-se o projeto, que contou, num primeiro momento, com reuniões que envolveram diretamente os professores responsáveis pelas disciplinas. Em sua metodologia foram realizados três encontros para a discussão das atividades a serem propostas. Em suas ações foram realizadas cinco atividades integradas, sendo organizadas por duas ou três disciplinas de forma conjunta, buscando assim, promover o diálogo e a prática interdisciplinar na escola. O projeto teve início no dia 13 de maio de 2015, data definida em razão da rememoração da assinatura da Lei Áurea, ocorrida em 1888, no contexto do Império.
A abordagem da temática através das atividades integradas realizou-se através de diferentes atividades. A Atividade 01, denominada de GRIÔT, envolveu as disciplinas de Língua Portuguesa, Ciências Biológicas e Literatura. Nesta atividade os alunos são contextualizados em relação à cultura africana. Fauna e flora africanas e a chegada dos africanos ao Brasil. A figura Griôt ${ }^{1}$ interpretada por uma pessoa da comunidade, sr. Dorvalino Conceição, 68 anos, onde destes 50 anos em Campo Bom, relatou aos alunos como foi a chegada dos afro-brasileiros na cidade e na comunidade, através da polarização industrial que ocorreu na cidade em virtude da necessidade de mão de obra para as fábricas de calçados. O sr. Dorvalino também relatou aos alunos as dificuldades de inserção dos negros na comunidade genuinamente germânica de Campo Bom nos anos passados.

Já a Atividade 02, denominada de RITOS E MITOS, estiveram envolvidas as disciplinas de História, Ensino Religioso e Língua Inglesa. Nesta atividade os alunos são contextualizados sobre 0 papel dos africanos na construção da cultura brasileira. Somos um país que culturalmente possui grande influência da cultura africana. Onde além de vocábulos, possuímos tradições brasileiras que são originárias da cultura africana. Assim como a culinária, ritmos musicais, danças e representações místicas, como as religiões de matriz africana que muito são discriminadas pelo desconhecimento da sua essência. Na etapa seguinte, a Atividade 03, intitulada MANIFESTAÇÕES CULTURAIS, envolveu as disciplinas Ed. Física, Música e Ed. Artística. Nesta atividade os alunos são contextualizados sobre as manifestações culturais brasileiras que tiveram origem através da cultura africana. Músicas; Danças; Máscaras africanas e todas as suas representações. É de compreensão popular que muitas das manifestações culturais brasileiras possuem sua origem em manifestações de origem africana. A

\footnotetext{
${ }^{1}$ O Griôt é um personagem importante na estrutura social da maioria dos países da África. É um guardião da tradição oral de seu povo, um especialista em genealogia e na história de seu povo. Tem como funções coletar e memorizar versos de antigas canções e épicos orais que são transmitidos geração após geração.
} 
capoeira como manifestação cultural de luta e dança; O samba como ritmo musical e prática dança, são alguns exemplos.

Atividade 04, chamada de RAÍZ "QUADRÁFRICA", as disciplinas de Matemática e Informática buscaram promover um diálogo interdisciplinar, através do qual os alunos foram contextualizados e estimulados a pensar em relação aos jogos de raciocínio de origem africana, assim como algoritmos africanos. Em alguns países da África os jogos de tabuleiro estão diretamente ligados à tradição das famílias, passados de geração em geração. Entre alguns povos, estes jogos são reservados exclusivamente aos homens, e utilizado para resolver conflitos entre eles. $\mathrm{Na}$ sua abordagem inicial, o jogo chamado Yoté, que é um jogo de confronto estratégico entre dois jogadores, é ensinado às crianças quando estão aptas ao raciocínio estratégico. Elas costumam traçar o tabuleiro na areia, utilizando como peças pequenos cocos, sementes, pedras ou outro recurso facilmente encontrado.

Em outra perspectiva do projeto, a Atividade 05 contemplou a questão das OCAS MALOCAS E QUILOMBOS. Neste caso, as disciplinas de Geografia e Educação Artística foram as responsáveis pela execução das atividades. Nesta etapa, os alunos foram contextualizados sobre os territórios negros, no estado do Rio Grande do Sul e na comunidade de Campo Bom, bem como sobre as representações construídas e difundidas sobre estes lugares de memória. Foram apresentadas imagens que retratavam a chegada dos negros africanos ao Rio Grande do Sul. Em especial na capital, Porto Alegre. Alguns monumentos, que hoje, são reconhecidos como territórios afro-brasileiros. A estrutura e funcionamento dos quilombos, dos anos de escravidão aos dias de hoje. Assim como a vinda de afro-brasileiros de diversas regiões do estado para a cidade de Campo Bom, com o objetivo de trabalharem nas fábricas de calçados. Além disso, foram promovidos momentos com os alunos para se pensar sobre o papel do negro nas demais culturas, como a ítalo, a germânica, entre outras.
A última atividade diretamente ligada ao projeto foi a SEMANA DA DIVERSIDADE. A semana ocorreu em novembro, junto à Semana da Consciência Negra e durante este período foi realizada a exposição de trabalhos realizados nas atividades integradas. Pensada como culminância do projeto, nesta exposição cada trabalho desenvolvido pelos alunos em cada uma das atividades integradas foi exposto ao olhar dos próprios alunos, alunos de escolas vizinhas, e comunidade escolar, todos convidados para acompanharem a semana.

Não apenas com o intuito de contemplação, mas sim com o objetivo de reflexão, de reconhecimento da cultura de um povo que teve grande influência no desenvolvimento do nosso estado e país. Povo que, diante do olhar dos livros didáticos que ainda valorizam em predominância a cultura ocidental, reflexo do pensamento de grande parte da nossa sociedade, é visto como inferior e muitas vezes em posição invisível. Não tendo, por consequência disso, o devido reconhecimento de sua importância em nossa história.

Trazendo também o exemplo de construção coletiva em sua abordagem interdisciplinar, na qual cada atividade foi pensada em conjunto, interligando disciplinas e agregando saberes. Neste contexto, a escola desempenhou um papel preponderante, na medida em que contribuiu - através da execução prática do projeto interdisciplinar - para a construção social da identidade étnico-racial (AMARO, 2015, p.127) no contexto escolar.

A avaliação deste projeto foi realizada de forma qualitativa, observando a participação dos alunos, o interesse na realização e envolvimento nas tarefas. As considerações finais - às quais a equipe envolvida com o projeto chegou - evidenciaram as limitações de se realizar um projeto de forma interdisciplinar dentro de um currículo mantido tradicional. Os docentes participantes destacaram o desafio de realizar atividades integradas interligando as disciplinas. Por outro lado, destacaram 0 envolvimento por parte dos alunos e da comunidade escolar, que se viu representada através das ações desenvolvidas pela escola. 
Ações interdisciplinares, como esta, permitem melhor compreender a dinâmica de funcionamento de ações possíveis, no caminho da educação transformadora. Ainda que partindo de um tema, originalmente situado na disciplina de História uma vez que caberia a esta disciplina estudar e aprofundar a história e a cultura das sociedades - a trajetória percorrida pelos alunos e professores da escola nos mostrou a possibilidade de romper com os silêncios do passado.

A proposta desenvolvida permitiu reafirmar o papel da escola - em consonância com a sociedade em transformação - na superação do racismo. Nesta perspectiva, a família, a escola e a sociedade, constituídas através de uma dinâmica de relações, aparecem como um caminho possível na superação do racismo e da intolerância (AMARO, 2015, p.143) que muitas vezes ofuscam as diferenças que constituem a diversidade dos nossos tempos.

\section{Considerações finais}

Esta pesquisa identificou que a partir da criação da principal política pública brasileira para a educação étnico-racial, a Lei 10639/2003, os currículos escolares passaram a abordar de forma mais abrangente a temática de História e Cultura Afro-Brasileira e Africana. Observa-se, ainda, neste mesmo contexto, que a partir de 2003, se difundem práticas pedagógicas integradas e interdisciplinares, que buscam romper com os limites, até então definidos para cada disciplina. A disciplina de História aparece neste campo, como um elemento de interlocução para o trabalho interdisciplinar na escola.

O conhecimento trazido pela disciplina de História permite melhor compreender a historicidade e a diversidade que constitui o tema das africanidades, em sua concepção mais ampla e moderna. A partir da relação passado-presente, torna-se possível avançar para outros campos do conhecimento, permitindo o aprofundamento de diferentes perspectivas culturais, que caracterizam as culturas de matriz africana.

Os artigos selecionados, na parte inicial da pesquisa, possibilitaram melhor compreender como ocorrem as práticas voltadas ao atendimento da legislação que trata do ensino das questões de matriz cultural africana, em diversos contextos. A análise evidenciou que nos doze primeiros anos em que Lei 10639/2003 esteve em vigor, poucos trabalhos sobre a temática foram encontrados nas bases de dados pesquisadas. Em relação às práticas, constatamos que a inserção do tema nos currículos escolares vem sendo realizada de forma lenta e superficial.

Como desafio para novas pesquisas, indica-se o aprofundamento do debate sobre a formação de professores para o ensino de história e cultura afrobrasileira e africana, bem como o impacto que as práticas pedagógicas exercem sobre o público atingido. O caso analisado no município de Campo Bom (RS) demonstra a emergência do tema no contexto escolar brasileiro. A GRIÔT, personagem da própria comunidade, utilizada para aproximar o tema com a realidade local - na qual os alunos da escola estavam inseridos - revela a potencialidade de rememoração sobre o passado da própria comunidade, que passa a dar visibilidade e significado à alguém do próprio lugar - cuja invisibilidade ainda se manifestava no imaginário coletivo dos moradores do bairro da escola.

Em comunidades, cujo passado ainda é representado quase que exclusivamente pela presença dos imigrantes europeus - como é o caso da imigração alemã em Campo Bom - a necessidade de se estabelecer políticas de ações afirmativas para a promoção do combate ao racismo e da igualdade racial, são questões urgentes.

\section{Referências}

AGUIAR, J. C. T. M.; AGUIAR, F. J. F. Uma reflexão sobre o ensino de história e cultura afrobrasileira e africana e a formação de professores em Sergipe. GEPIADDE, Ano 4, Volume 7. janjun de 2010 .

AMARO, Sarita. Racismo, igualdade racial e políticas de ações afirmativas no Brasil. Porto Alegre: EdiPUCRS, 2015.

ARANHA, M. L. A. História da educação e da Pedagogia: Geral e Brasil. São Paulo: Moderna, 2006. 
ARAÚJO, P. L.; YOSHIDA, S. M. P. F. Professor: Desafios da prática pedagógica na atualidade. Disponível em: http://www.ice.edu.br/TNX/storage/webdisco/200 9/11/03/outros/608f3503025bdeb70200a86b2b8 9185a.pdf. Acesso em 20/06/2016.

BARBOSA, C. C.; SOUZA, A. D.; CORDEIRO, A. C. V.; LIMA ,A. C.; SOARES, A. F.; NEPOMUCENO, C. R.; SILVA, D. P.; OLIVEIRA, D. M.; REIS, D. S.; VIEIRA, L. S.; PEREIRA, L. R.; PEREIRA, M. V. V.; BARBOSA, M. F. S.; SILVA, R. A.; PEREIRA, S. J. M.; OLIVEIRA, S. L. F.; FREITAS, S. G. HISTÓRIA E CULTURA AFROBRASILEIRA E AFRICANA: DESAFIOS E PERSPECTIVAS. XXVI Simpósio Nacional de História. Natal-RN, 2003

BAUMAN, Z. Globalização - as consequências humanas. Rio de Janeiro: Zahar, 2000.

BERNARDINO, J. Ação Afirmativa e a Rediscussão do Mito da Democracia Racial no Brasil. Disponível em:< http://www.scielo.br/pdf/eaa/v24n2/a02v24n2. Acesso em: 02 de jun. 2016.

BRASIL. CAPES. Documento de Área Interdisciplinar. Brasília, 2013, 85p. Disponível em: http://www.capes.gov.br/images/stories/downloa d/avaliacaotrienal/Docs de area/Interdisciplinar doc area e comiss\%C3\%A30 ATT27SET.pdf. Acesso em 06 set. 2016.

História e Cultura Afro-Brasileira. Lei Federal $n^{\circ}$ 10.639/2003. Disponível em: http://www.planalto.gov.br/ccivil 03/Leis/2003/L1 0.639.htm. Acesso em 14/05/2016.

Diretrizes Curriculares Nacionais para a Educação das Relações Étnico-raciais e para o Ensino de História e Cultura Afro-Brasileira e Africana. Conselho Nacional de Educação, 2004. Disponível em: http://portal.mec.gov.br/cne/arquivos/pdf/res0120 04.pdf. Acesso em 14/05/2016.

CARDOSO, S. R.; FEITOSA, D. M. Ensino da história e cultura afro-brasileira nos currículos oficiais: desafios na formação docente. Revista do Departamento de Fundamentos da Educação da Universidade Federal do Piauí, v.2, n.1, 2015, p. 82-97.

CASTRO, C. G. C. S.; ARAÚJO, D. C.; CEBULSKI, M. C.; MARÇAL, M. A. O ensino de história e cultura afro-brasileira e africano no Paraná: legislação, politicas afirmativas e Formação docente. EDUCERE 2008.

COÊLHO, F. F.; COSTA, W. N. C. A abordagem da história e da cultura afro-brasileira pelos professores de matemática: o papel dos livros didáticos. Anais do $X$ Encontro Nacional de Educação Matemática Comunicação Científica. Bahia, jul. 2010.
COELHO, W. N. B.; COELHO, N. C. Os conteúdos étnico-raciais na educação brasileira: práticas em curso. Educar em Revista, Curitiba, n. 47, jan./mar. 2013, p. 67-84.

COSTA, R. L. S.; DUTRA, D. F. A lei 10639/2003 e o ensino de geografia: representação dos negros e África nos livros didáticos. Porto Alegre, Encontro Nacional de Práticas de Ensino em Geografia, ago./set. 2009.

FILIPE, R. C. G. Raça e classe na gestão da educação brasileira. Tese (Doutorado em Educação). Programa de Pós-Graduação em Educação, Universidade de Brasília, Brasília, 2010.

FERNANDES, J. R. O. Ensino de história e diversidade cultural: desafios possibilidades. Cad. Cedes, Campinas, v. 25, n. 67, set./dez. 2005, p. 378-388.

FERREIRA, C. M. S. Formação de professores à luz da história e cultura afro-brasileira e africana: nova tendência, novos desafios para uma prática reflexiva. Revista Eletrônica Acolhendo a Alfabetização nos Países de Língua Portuguesa. 2005.

GOMES, I. L. Diversidade étnico-racial, inclusão e equidade na educação brasileira: desafios, políticas e práticas. ANPAE 2010.

GUEDES, E.; NUNES, P.; ANDRADE, T. O uso da lei 10.639/03 em sala de aula. Revista LatinoAmericana de História, v. 2, n. 6, ago. 2013.

JUNG, Carlos Fernando. Metodologia para pesquisa e desenvolvimento. Rio de Janeiro: Axcel Books do Brasil, 2004.

KADLUBITSKI, L.; JUNQUEIRA, S. Diversidade cultural na formação do pedagogo. IX Congresso Nacional de Educação. EDUCERE. 2009.

KOLODZIEISKI, J. F. Ensino da História e Cultura Afro- Brasileira e Africana: professores paranaenses falando sobre a implementação da lei nas aulas de matemática. Encontro Brasileiro de Estudantes de Pós-Graduação em Educação Matemática, 2013, Vitória/ES.

MOREIRA, M. A.; SANTANA, J. V. J. Formação docente frente ao ensino de história e cultura afro-brasileira: reflexões a partir do município de Itambé/BA. V FIPED Fórum Internacional de Pedagogia 2013.

MULLER, T. R. Tecendo tramas, traçando gentes: narrativas constituindo identidades em uma escola municipal de Porto Alegre/RS no ensino da história e cultura africana e afro-brasileira. 2009. Dissertação de Mestrado, UFRGS, Porto Alegre, 2009. 
PACIFICO, T. M. A implantação da lei $n^{\circ}$ 10.639/2003 em uma escola da rede pública estadual, no ensino fundamental, na cidade de Curitiba - PR, 2008, p. 561-571.

PAULA, B. X.; GUIMARÃES, S. 10 anos da lei federal $n^{\circ} 10.639 / 2003$ e a formação de professores: uma leitura de pesquisas científicas. Educ. Pesqui., São Paulo, v. 40, n. 2, p. 435-448, abr./jun. 2014.

PENA, R. F. A. Composição étnica do Brasil. Brasil Escola. Disponível em http://brasilescola.uol.com.br/geografia/composic ao-etnica-brasileira.htm. Acesso em 27 de maio de 2016.

PEREIRA, D. S. G.; JUNG, C. F. A Criatividade e a Inovação nas Organizações. Congresso Internacional de Administração. 2014.

PEREIRA, J. S. Reconhecendo ou construindo uma polaridade étnico-identitária? Desafios do ensino de história no imediato contexto pós-Lei no 10.639. Estudos Históricos, Rio de Janeiro, vol. $21, n^{\circ} 41$, janeiro-junho de 2008, p. 21-43.
PIRES, C. L. Z. Território, Significações Etnoculturais e Educação. Porto Alegre: UFRGS. 2008.

ROSA, M. C. Os professores de arte e a inclusão: o caso da lei 10639/2003. GT: Afro-brasileiros e Educação/ n. 21/2012.

SULEIMAN, B.B. Relações étnico-raciais e formação de professores. Revista Quadrimestral da Associação Brasileira de Psicologia Escolar e Educacional, SP. v. 18, n.2, mai./ago. 2014, p. 369-372.

VALENTE, A. L. Ação afirmativa, relações raciais e educação básica. Revista Brasileira de Educação, n. 38, jan /fev /mar /abr 2005, p. 6276.

VERRANGIA, D.; SILVA, P. B. G. Cidadania, relações étnico-raciais e educação: desafios e potencialidades do ensino de Ciências. Educação e Pesquisa, São Paulo, v. 36, n.3, set./dez. 2010, p. 705-718. 